\title{
Widespread regulation of gene expression by glucocorticoids in chondrocytes from patients with osteoarthritis as determined by RNA-Seq
}

Antti Pemmari ${ }^{1} \mathbb{1}$, Tiina Leppänen ${ }^{1}$, Mari Hämäläinen ${ }^{1}$, Teemu Moilanen ${ }^{1,2}$, Katriina Vuolteenaho ${ }^{1}$ and Eeva Moilanen ${ }^{1 *}$

\begin{abstract}
Background: Intra-articular glucocorticoid (GC) injections are widely used as a symptomatic treatment for osteoarthritis (OA). However, there are also concerns about their potentially harmful effects, and their detailed effects on chondrocyte phenotype remain poorly understood.

Methods: We studied the effects of dexamethasone on gene expression in OA chondrocytes with RNA-Seq. Chondrocytes were isolated from the cartilage from OA patients undergoing knee replacement surgery and cultured with or without dexamethasone for $24 \mathrm{~h}$. Total RNA was isolated and sequenced, and functional analysis was performed against the Gene Ontology (GO) database. Results for selected genes were confirmed with RT-PCR. We also investigated genes linked to OA in recent genome-wide expression analysis (GWEA) studies.

Results: Dexamethasone increased the expression of 480 and reduced that of 755 genes with a fold change (FC) 2.0 or greater. Several genes associated with inflammation and cartilage anabolism/catabolism as well as lipid and carbohydrate metabolism were among the most strongly affected genes. In the GO analysis, genes involved in the extracellular matrix organization, cell proliferation and adhesion, inflammation, and collagen synthesis were enriched among the significantly affected genes. In network analysis, NGF, PI3KR1, and VCAM1 were identified as central genes among those most strongly affected by dexamethasone.

Conclusions: This is the first study investigating the genome-wide effects of GCs on the gene expression in OA chondrocytes. In addition to clear anti-inflammatory and anticatabolic effects, GCs affect lipid and glucose metabolism in chondrocytes, an observation that might be particularly important in the metabolic phenotype of OA.
\end{abstract}

Keywords: Osteoarthritis, Cartilage, Chondrocyte, Glucocorticoid, RNA-Seq

\footnotetext{
* Correspondence: eeva.moilanen@tuni.fi

${ }^{1}$ The Immunopharmacology Research Group, Faculty of Medicine and Health Technology, Tampere University and Tampere University Hospital, Tampere, Finland

Full list of author information is available at the end of the article
}

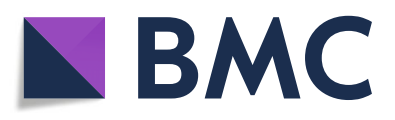

(- The Author(s). 2020 Open Access This article is licensed under a Creative Commons Attribution 4.0 International License, which permits use, sharing, adaptation, distribution and reproduction in any medium or format, as long as you give appropriate credit to the original author(s) and the source, provide a link to the Creative Commons licence, and indicate if changes were made. The images or other third party material in this article are included in the article's Creative Commons licence, unless indicated otherwise in a credit line to the material. If material is not included in the article's Creative Commons licence and your intended use is not permitted by statutory regulation or exceeds the permitted use, you will need to obtain permission directly from the copyright holder. To view a copy of this licence, visit http://creativecommons.org/licenses/by/4.0/. The Creative Commons Public Domain Dedication waiver (http://creativecommons.org/publicdomain/zero/1.0/) applies to the data made available in this article, unless otherwise stated in a credit line to the data. 


\section{Introduction}

Osteoarthritis (OA) is a disease that affects over $15 \%$ of the global population aged 60 or more, causing pain, disability, and reduced quality of life, as well as major costs to healthcare systems [1]. The disease process in the joint is characterized by oxidative stress, low-grade inflammation, and increased catabolism. This eventually results in the breakdown of the articular cartilage and changes in other tissues of the joint, leading to pain and loss of function [2].

Chondrocyte gene expression is markedly altered in osteoarthritis [3]. Some of these changes are thought to be harmful (such as increased expression of proteolytic enzymes and proinflammatory cytokines) and some protective (e.g., increased expression of extracellular matrix [ECM] components) [4]. A couple of genomewide expression analyses (GWEAs) have previously been performed comparing damaged OA cartilage either to intact OA cartilage or to cartilage from a healthy donor [5-8]. Two larger studies have utilized microarrays and RNA-Seq respectively to compare lesioned and healthy OA cartilage in the same joint, identifying a number of differentially expressed genes involved in inflammation, skeletal system development, cell adhesion, and monosaccharide metabolism $[9,10]$.

As no proven disease-modifying medications are currently available for $\mathrm{OA}$, all pharmacological treatments are essentially symptomatic [1]. Intra-articular injections with glucocorticoids (GCs) are widely used to combat inflammation and pain and are recommended in the OARSI [11], ACR [12], and NICE [13] treatment guidelines for the management of knee OA. However, their long-term benefits are unclear, and there appears to be a significant variation in the responses between individual patients [14]. GCs are thought to suppress harmful lowgrade inflammation present in OA joints. However, there are some concerns about potentially deleterious long-term effects $[15,16]$.

Glucocorticoids are steroid hormones that are endogenously produced in the adrenal cortex. In target cells, they form a complex with glucocorticoid receptor (GR), which then dimerizes and migrates into the nucleus. After that, GCs cause their anti-inflammatory effects through two main mechanisms. The GR-steroid complex binds to glucocorticoid response elements (GREs) in the promoter region of target genes, promoting the expression of anti-inflammatory genes as well as a number of genes involved in various other functions. In addition, GCs can inhibit the activity of inflammatory transcription factors such as nuclear factor kappa-lightchain-enhancer of activated $B$ cells $(N F-\kappa B)$ and activator protein 1 (AP-1) and sequester their coactivators, leading to suppression of the expression of various inflammatory genes and attenuation of inflammation [17].
In chondrocytes, glucocorticoids have also been shown to reduce chondrocyte viability by inducing oxidative stress and apoptosis [18]. In addition to their effects on inflammation, modulation of glucose and lipid metabolism by glucocorticoids could mediate some of their effects on OA cartilage. Osteoarthritis is linked to metabolic disturbances such as obesity and diabetes, giving rise to the concept of a so-called metabolic phenotype of OA. There is also evidence on metabolic derangements in articular chondrocytes, and impairments in, for example, glycolysis [19], cholesterol metabolism, [20], and mitochondrial respiration [21] have been reported. Due to their established effects on these metabolic pathways in other cell types [22], glucocorticoids could plausibly affect OA pathogenesis via affecting chondrocyte metabolism.

In the present study, we set out to study the effects of the glucocorticoid dexamethasone on gene expression in OA chondrocytes. The aim was to identify significantly modulated pathways and/or functional categories of genes that might be important in the pathogenesis of OA. The results were also compared to those of two previous GWEA studies based on the patient material of the RAAK study $[9,10]$ to determine whether glucocorticoid treatment might "shift" the expression profile of OA chondrocytes towards the one in healthy cells. In addition, we studied the effects of dexamethasone on potential OA susceptibility genes previously identified in genome-wide association (GWAS) studies [23-25].

\section{Methods}

\section{Patients and cell culture}

Leftover cartilage pieces were collected from OA patients ( $n=10$, BMI $27.3[5.8] \mathrm{kg} / \mathrm{m}^{2}$, age 70.0 [14.8] years, median [IQR]; 4/6 females/males) undergoing total knee replacement surgery in Coxa Hospital for Joint Replacement, Tampere, Finland. All patients fulfilled the American College of Rheumatology classification criteria for knee OA [26] with a mean Kellgren-Lawrence score of 3.5 (SEM 0.22 ). Patients with diabetes mellitus were excluded from the study.

Chondrocyte isolation and culture were performed as previously described [27]. The articular cartilage was removed aseptically from the subchondral bone using a scalpel and cut into small pieces. The pieces were first washed with phosphate-buffered saline (PBS). After that, they were incubated overnight in the presence of Liberase $^{\mathrm{rm}}$ enzyme (Roche Applied Science, Penzberg, Germany, $0.25 \mathrm{mg} / \mathrm{mL}$ ) diluted in Dulbecco's modified Eagle's medium (DMEM, Sigma-Aldrich, St Louis, MO, USA) with GlutaMAX-I containing penicillin (100 units $/ \mathrm{mL}$ ), streptomycin $(100 \mu \mathrm{g} / \mathrm{mL})$, and amphotericin B (250 ng/ $\mathrm{mL}$ ) (all three from Invitrogen, Carlsbad, CA, USA) at $37^{\circ} \mathrm{C}$. The resulting cell suspension was poured through a $70-\mu \mathrm{m}$ nylon mesh and centrifuged for $5 \mathrm{~min}$ at $1500 \mathrm{rpm}$. 
The cells were washed and seeded on 24-well plates $(0.2$ million cells $/ \mathrm{mL}$ ) and incubated for $24 \mathrm{~h}$. Thereafter, the experiments were started by adding dexamethasone $(1 \mu \mathrm{M})$ in the fresh culture medium (DMEM supplemented with 10\% heat-inactivated fetal bovine serum [Lonza] together with the aforementioned substituents) for $24 \mathrm{~h}$.

\section{Enzyme-linked immunosorbent assay}

A separate group of nine cartilage samples was used for ELISA measurements. Cartilage preparation, chondrocyte isolation, and incubation were performed as described above. After $24 \mathrm{~h}$, incubations were terminated by collecting the cell culture media, and culture medium samples were stored at $-20^{\circ} \mathrm{C}$ until analyzed. The concentrations of human MMP1, MMP-13, and CCL2 (MCP-1) were determined by enzyme-linked immunosorbent assay (ELISA) by using reagents from R\&D Systems Europe Ltd., 175 Abingdon, UK (catalog nos. DY901, DY511, and DY279, respectively). The detection limits were 39 $\mathrm{pg} / \mathrm{mL}, 31.3 \mathrm{pg} / \mathrm{mL}$, and $7.8 \mathrm{pg} / \mathrm{mL}$, respectively.

\section{RNA isolation and sample preparation}

The culture medium was removed at the indicated time point, and total RNA of the chondrocytes was extracted with GenElute $^{\mathrm{Tm}}$ Mammalian Total RNA Miniprep kit (Sigma). Total RNA was treated with DNAse I (Qiagen, Hilden, Germany). RNA concentration and integrity were confirmed with the 2100 Bioanalyzer (Agilent Technologies). RNA ( $150 \mathrm{ng} / \mathrm{sample})$ was reverse-transcribed to cDNA for RT-PCR using TaqMan Reverse Transcription reagents and random hexamers (Applied Biosystems, Foster City, CA, USA).

\section{Next-generation sequencing and data analysis}

Sequencing of RNA samples (500 ng) was performed in the Finnish Institute of Molecular Medicine (FIMM) sequencing core, Helsinki, Finland, using the Illumina HiSeq 2500 sequencing platform. Sequencing depth was 15 million paired-end reads $100 \mathrm{bp}$ in length. Read quality was first assessed using FastQC [28], and the reads were trimmed using Trimmomatic [29]. Trimmed reads were aligned to the full reference human genome with STAR [30]. Count matrices were prepared with the featureCounts program [31]. Differential expression was assessed with DESeq2 using patient number as an additional experimental factor for pairwise comparisons [32]. Gene expression levels are given as DESeq2normalized counts, and genes with a mean normalized count 5 or less across all samples were excluded from further analysis. For the purposes of further analysis, genes with a minimum of 2.0 fold change $(\mathrm{FC})$ in abundance and false discovery rate (FDR)-corrected $p$ value $<0.05$ were deemed biologically and statistically significant. Functional analysis was performed against the Gene Ontology (GO) database [33] using ranked list enrichment implemented in the GOrilla tool [34], and protein interactions were studied with STRING [35]. Gene functions were obtained from the NCBI Gene database.

\section{Quantitative reverse transcription/polymerase chain reaction}

cDNA obtained from the reverse transcriptase reaction was diluted 1:20 with RNAse-free water and subjected to quantitative RT-PCR using TaqMan Universal PCR Master Mix and the ABI Prism 7500 Sequence detection system (Applied Biosystems).

Primers and probes for human glyceraldehyde-3phosphate dehydrogenase (GAPDH), cyclooxygenase-2 (COX-2), MAP kinase phosphatase 1 (MKP-1), matrix metalloproteinases (MMPs) 1 and 13, collagen type II, alpha 1 (COL2A1), and aggrecan (ACAN) were obtained from Metabion International AG (Martinsried, Germany). The primer and probe sequences (Table S1) and concentrations were optimized according to the manufacturer's instructions in TaqMan Universal PCR Master Mix Protocol part number 4304449 revision C. mRNA levels of other studied genes were determined with TagMan Gene Expression Assays (Applied Biosystems): MMP16 (assay number Hs00234676_m1), collagen type IX, alpha 1 (COL9A1, Hs00932136_g), collagen type XI, alpha 1 (COL11A1, Hs01097664_m1), C-C motif chemokine ligand 2 (CCL2, Hs00234140_m1), MAP kinase phosphatase 2 (MKP-2, Hs01027785_m1), Kruppel like factor 9 (KLF9, Hs00230918_m1), nerve growth factor (NGF, Hs00171458_m1), tumor necrosis factor superfamily member 15 (TNFSF15, Hs00270802_s1), and forkhead box O3 (FOXO3, Hs00818121_m1).

PCR reaction parameters were as follows: incubation at $50^{\circ} \mathrm{C}$ for $2 \mathrm{~min}$, incubation at $95^{\circ} \mathrm{C}$ for $10 \mathrm{~min}$, and thereafter 40 cycles of denaturation at $95^{\circ} \mathrm{C}$ for $15 \mathrm{~s}$ and annealing and extension at $60^{\circ} \mathrm{C}$ for $1 \mathrm{~min}$. Each experimental reaction was performed in duplicate. The relative mRNA levels of genes listed in Table S1 were quantified using the standard curve method as described in Applied Biosystems User Bulletin number 2. To calculate the relative expression of mRNAs determined with TaqMan assays, the $2^{(-\Delta \Delta C T)}$ method was used. According to the method, the cycle threshold $\left(C_{\mathrm{T}}\right)$ value for genes of each gene was normalized to the $C_{T}$ value of GAPDH mRNA in the same sample.

\section{Statistics}

For NGS data analysis, normalization was performed and differential expression studied using a negative binomial model implemented in DESeq2. In ELISA and PCR 
Table 1 Twelve most strongly up- and downregulated genes in dexamethasone-treated OA chondrocytes (D) relative to control (Co)

\begin{tabular}{|c|c|c|c|c|c|c|}
\hline \multicolumn{7}{|c|}{ Genes most strongly upregulated by dexamethasone } \\
\hline Gene & Name & Function & $\begin{array}{r}\text { Mean } \\
(\mathrm{Co})\end{array}$ & $\begin{array}{r}\text { Mean } \\
\text { (D) }\end{array}$ & $\begin{array}{r}\text { Fold } \\
\text { change }\end{array}$ & FDR $p$ \\
\hline GPM6B & Glycoprotein M6B & Regulation of osteoblast function & 205.4 & 8033.4 & 37.53 & $<0.0001$ \\
\hline SULT1B1 & Sulfotransferase family 1B member 1 & Sulfation & 14.5 & 702.2 & 34.30 & $<0.0001$ \\
\hline KLRD1 & Killer cell lectin like receptor D1 & Regulation of inflammation & 15.1 & 685.0 & 29.24 & $<0.0001$ \\
\hline FLRT3 & $\begin{array}{l}\text { Fibronectin leucine rich transmembrane } \\
\text { protein } 3\end{array}$ & Cell adhesion & 6.9 & 247.4 & 27.28 & $<0.0001$ \\
\hline FAM83A-AS1 & FAM83A antisense RNA 1 & Regulation of cell proliferation & 0.4 & 43.6 & 21.41 & $<0.0001$ \\
\hline ZBTB16 & $\begin{array}{l}\text { Zinc finger and BTB domain containing } \\
16\end{array}$ & Cartilage development & 113.9 & 2490.2 & 21.11 & $<0.0001$ \\
\hline FKBP5 & FK506 binding protein 5 & Glucocorticoid receptor regulation & 702.8 & 15089.3 & 20.11 & $<0.0001$ \\
\hline PDK4 & Pyruvate dehydrogenase kinase 4 & Glucose and lipid metabolism & 251.6 & 5804.9 & 19.84 & $<0.0001$ \\
\hline PTK2B & Protein tyrosine kinase 2 beta & Regulation of cell proliferation & 116.6 & 2393.8 & 19.43 & $<0.0001$ \\
\hline ABCD2 & $\begin{array}{l}\text { ATP binding cassette subfamily } D \\
\text { member } 2\end{array}$ & Lipid metabolism & 13.8 & 340.3 & 18.77 & $<0.0001$ \\
\hline $\mathrm{HAL}$ & Histidine ammonia-lyase & Histidine metabolism & 5.5 & 176.0 & 16.34 & $<0.0001$ \\
\hline GLUL & Glutamate-ammonia ligase & Cell proliferation & 3886.9 & 64025.9 & 15.67 & $<0.0001$ \\
\hline \multicolumn{7}{|c|}{ Genes most strongly downregulated by dexamethasone } \\
\hline Gene & Name & Function & $\begin{array}{r}\text { Mean } \\
(\mathrm{Co})\end{array}$ & $\begin{array}{r}\text { Mean } \\
\text { (D) }\end{array}$ & $\begin{array}{r}\text { Fold } \\
\text { change }\end{array}$ & FDR $p$ \\
\hline PLAU & Plasminogen activator, urokinase & Cell proliferation and migration & 169.7 & 9.5 & -14.03 & $<0.0001$ \\
\hline INHBA & Inhibin beta A subunit & $\begin{array}{l}\text { Cell proliferation and } \\
\text { differentiation }\end{array}$ & 26339.5 & 2220.8 & -11.71 & $<0.0001$ \\
\hline P2RY6 & Pyrimidinergic receptor P2Y6 & Inflammation & 114.3 & 7.6 & -10.56 & $<0.0001$ \\
\hline VCAM1 & Vascular cell adhesion molecule 1 & Inflammation & 24663.5 & 2854.2 & -8.51 & $<0.0001$ \\
\hline GREM1 & Gremlin 1, DAN family BMP antagonist & $\begin{array}{l}\text { Chondrocyte proliferation and } \\
\text { differentiation }\end{array}$ & 6327.8 & 691.8 & -8.22 & $<0.0001$ \\
\hline HAS2 & Hyaluronan synthase 2 & ECM production & 1922.7 & 234.2 & -8.11 & $<0.0001$ \\
\hline SLC26A4 & Solute carrier family 26 member 4 & Anion transport & 1537.7 & 180.9 & -7.73 & $<0.0001$ \\
\hline ARSI & Arylsulfatase family member I & Glycosphingolipid metabolism & 102.6 & 11.7 & -7.46 & $<0.0001$ \\
\hline MXRA5 & Matrix remodeling associated 5 & TGF $\beta$ signaling & 1100.1 & 132.2 & -7.31 & $<0.0001$ \\
\hline MYBPH & Myosin binding protein $\mathrm{H}$ & Cell adhesion & 57.6 & 5.7 & -7.21 & $<0.0001$ \\
\hline TSPAN2 & Tetraspanin 2 & Cell migration & 1192.6 & 154.4 & -7.11 & $<0.0001$ \\
\hline NGF & Nerve growth factor & Pain & 129.1 & 16.2 & -6.92 & $<0.0001$ \\
\hline
\end{tabular}

FDR $p=$ False discovery rate -corrected $p$-value

experiments, paired Student's $t$ test was used to assess the statistical significance of differential expression, and multiple testing was addressed using Bonferroni correction. Data is presented as average + standard error of the mean (SEM).

\section{Results}

\section{Differentially expressed genes}

After normalization and correction for multiple testing, 480 genes were upregulated more than 2.0-fold in dexamethasone-treated cells compared to control cells, and 755 downregulated by the same factor $(\mathrm{FC}<-2.0)$. In total, 7371 genes were found to be differentially expressed in dexamethasone-treated versus control cartilage in a statistically significant manner (FDR-corrected $p$ value <0.05). Of these, 3612 were up- and 3759 downregulated. Twelve most strongly up- and downregulated genes are listed in Table 1. A complete list of differentially expressed genes in dexamethasone-treated chondrocytes compared to untreated cells is provided in the Supplementary data in Table S2.

The list of the most strongly upregulated genes includes genes involved in the regulation of cell proliferation, inflammation, cartilage development, and carbohydrate and lipid metabolism. Among the most strongly downregulated genes are those linked to cell proliferation and differentiation, extracellular matrix production, and inflammation. Also included was nerve growth factor (NGF), a known mediator of OA pain [36] (Table 1). 
Table 2 Ranked Gene Ontology (GO) terms significantly affected by dexamethasone

\begin{tabular}{|c|c|c|}
\hline GO term & Description & FDR $p$-value \\
\hline GO:0048523 & Negative regulation of cellular process & 3.50E-08 \\
\hline GO:0032502 & Developmental process & $3.81 \mathrm{E}-08$ \\
\hline GO:0048519 & Negative regulation of biological process & 4.05E-08 \\
\hline GO:0030334 & Regulation of cell migration & 5.17E-08 \\
\hline GO:0051239 & Regulation of multicellular organismal process & 1.69E-07 \\
\hline GO:0032501 & Multicellular organismal process & 4.37E-07 \\
\hline GO:0007166 & Cell surface receptor signaling pathway & 4.66E-07 \\
\hline GO:0043062 & Extracellular structure organization & $6.75 \mathrm{E}-06$ \\
\hline GO:0030198 & Extracellular matrix organization & 7.34E-06 \\
\hline GO:0048856 & Anatomical structure development & 7.86E-06 \\
\hline GO:0032879 & Regulation of localization & 7.91E-06 \\
\hline GO:0009725 & Response to hormone & $1.25 \mathrm{E}-05$ \\
\hline GO:0042127 & Regulation of cell proliferation & $1.27 \mathrm{E}-05$ \\
\hline GO:0050896 & Response to stimulus & $3.12 \mathrm{E}-05$ \\
\hline GO:0040011 & Locomotion & 0.000137 \\
\hline GO:0048518 & Positive regulation of biological process & 0.000193 \\
\hline GO:0050794 & Regulation of cellular process & 0.000197 \\
\hline GO:0040008 & Regulation of growth & 0.000199 \\
\hline GO:0048583 & Regulation of response to stimulus & 0.000351 \\
\hline GO:0065008 & Regulation of biological quality & 0.000584 \\
\hline GO:0043408 & Regulation of MAPK cascade & 0.00105 \\
\hline GO:0009719 & Response to endogenous stimulus & 0.00152 \\
\hline GO:0006954 & Inflammatory response & 0.00235 \\
\hline GO:0006950 & Response to stress & 0.00241 \\
\hline GO:0065007 & Biological regulation & 0.00281 \\
\hline GO:0051174 & Regulation of phosphorus metabolic process & 0.00303 \\
\hline GO:0010273 & Detoxification of copper ion & 0.00306 \\
\hline GO:0048878 & Chemical homeostasis & 0.0032 \\
\hline GO:0010941 & Regulation of cell death & 0.00426 \\
\hline GO:0070482 & Response to oxygen levels & 0.00506 \\
\hline GO:0061687 & Detoxification of inorganic compound & 0.0057 \\
\hline GO:0006928 & Movement of cell or subcellular component & 0.00578 \\
\hline GO:0022610 & Biological adhesion & 0.00626 \\
\hline GO:0009611 & Response to wounding & 0.0064 \\
\hline GO:0007155 & Cell adhesion & 0.00717 \\
\hline GO:0065009 & Regulation of molecular function & 0.0116 \\
\hline GO:0051338 & Regulation of transferase activity & 0.023 \\
\hline GO:0006068 & Ethanol catabolic process & 0.0239 \\
\hline GO:0019216 & Regulation of lipid metabolic process & 0.0255 \\
\hline GO:0009628 & Response to abiotic stimulus & 0.0342 \\
\hline GO:0006109 & Regulation of carbohydrate metabolic process & 0.0375 \\
\hline GO:0051246 & Regulation of protein metabolic process & 0.039 \\
\hline GO:0002682 & Regulation of immune system process & 0.0425 \\
\hline GO:0032964 & Collagen biosynthetic process & 0.0429 \\
\hline GO:0008283 & Cell proliferation & 0.0454 \\
\hline
\end{tabular}

FDR $p$-value $=$ False discovery rate -corrected $p$-value 
Next, we studied, by ranked list enrichment GO analysis, which functional gene categories were enriched among those genes with the largest fold changes into either direction (Table 2). These include, among others, those associated with extracellular matrix organization, regulation of cell proliferation, inflammatory response, cell adhesion, MAP kinase signaling, collagen synthesis, and lipid and carbohydrate metabolism.

\section{Genes involved in inflammation, oxidative stress, and extracellular matrix production}

As low-grade inflammation, oxidative stress, and changes in extracellular matrix production and catabolism are central features in the pathogenesis of OA, we set out to separately study genes linked to these processes (Table 3). Several proinflammatory factors such as cyclooxygenase-2 (COX-2, fold change -4.29 ), chemokine (C-C motif) ligand 2 (CCL2, fold change -5.43 ), and TNF superfamily member 15 (TNFSF15, fold change -5.98) were significantly downregulated by dexamethasone, while the antiinflammatory MAP kinase phosphatases 1 (MKP-1, fold change 10.48) and 2 (MKP-2, fold change 5.50) were upregulated. Genes affecting response to oxidative stress, such as Kruppel-like factor 9 (KLF9, fold change 10.85) and forkhead box O3 (FOXO3, fold change 4.29), were similarly upregulated. Also, the catabolic matrix metalloproteinases 1,16 , and 13 (MMP1 with fold change - 2.85, MMP16 with fold change - 3.12 and MMP13 with fold change -4.08) were downregulated by dexamethasone. Various collagens were downregulated by dexamethasone, including the most highly expressed collagens COL2A1 (fold change -2.28) and COL11A1 (fold change - 3.12). However, aggrecan was found to be significantly upregulated (fold change 2.43). The expression of connective tissue growth factor (CTGF, fold change 2.25) was enhanced while fibroblast growth factor 1 (FGF1, fold change -2.62), transforming growth factor beta 2 (TGFB2, fold change -2.57), and vascular endothelial growth factor A (VEGFA, fold change - 2.36) were downregulated by dexamethasone. The change in the expression of selected genes was confirmed with RT-PCR (Table S3) and the production of MMPs 1 and 13 as well as CCL2 with ELISA (Figure S1).

\section{Carbohydrate and lipid metabolism}

As glucocorticoids regulate glucose and lipid metabolism, and $\mathrm{OA}$ is known to be associated with metabolic syndrome, we separately studied genes for proteins participating in the main pathways of carbohydrate and lipid metabolism (glycolysis, oxidative phosphorylation, lipolysis, and betaoxidation) [37]. Dexamethasone did not have a marked (fold change $>2.0$ ) effect on any of these genes, with the sole exception being upregulation of long-chain acyl-CoA dehydrogenase (ACADL) (fold change 2.60) (Table S4).
However, dexamethasone affected the expression of several other genes regulating lipid and carbohydrate metabolism (those associated with hierarchically highlevel GO terms GO:0019216 Regulation of lipid metabolism and GO:0006109 Regulation of carbohydrate metabolism). For example, pyruvate dehydrogenase kinase 4 (PDK4) and glycogen phosphorylase L (PYGL), as well as the redox regulator Sestrin 3 (SESN3), were markedly upregulated by dexamethasone (Fig. 1).

\section{Integration with previous GWAS and GWEA studies}

When the 53 genes previously associated with $\mathrm{OA}$ in GWAS studies [23-25] were studied separately, 12 of them were found to be significantly affected by dexamethasone with a FC greater than 2.0 (Table S5). Eleven of them (including COL11A1, COX-2, GDF5, IL6, and VEGFA) were downregulated and only one, IL16, upregulated.

The microarray-based GWEA study by Ramos et al. [9] identified 18 genes that were differentially expressed between degraded and preserved OA cartilage in the same joint, and two of them were affected by dexamethasone in our data (Table S6). Of these, the expression of COL9A1 was found to be lower in degraded cartilage, and the gene was also downregulated by dexamethasone. Nerve growth factor (NGF), in turn, was expressed at higher levels in degraded cartilage and strongly downregulated by dexamethasone.

Almeida et al. [10] analyzed gene expression in degraded and spared OA cartilage with NGS. In their data, 372 genes were differentially expressed with FC $>2.0$ into either direction, and 78 of them were significantly affected by dexamethasone (FC $>2.0$ into either direction) in the present study. Of these, 19 were upregulated in degraded cartilage compared with spared cartilage, and upregulated by dexamethasone in our data, while 25 were upregulated in degraded cartilage and downregulated by dexamethasone. Seventeen were downregulated in degraded cartilage and by dexamethasone, while another 17 were downregulated in degraded cartilage and upregulated by dexamethasone. Interestingly, NGF was one of the genes whose expression was enhanced in degraded OA cartilage and normalized by dexamethasone (Table S7).

\section{Interactions between the differentially expressed genes}

Among the genes most strongly affected by dexamethasone ( $F C>5.0)$, several interactions were identified using the STRING database (Fig. 2). Phosphatidylinositol 3kinase regulatory subunit alpha (PI3KR1), vascular cell adhesion protein 1 (VCAM1), KIT proto-oncogene receptor tyrosine kinase (KIT), FGR proto-oncogene Src family tyrosine kinase (FGR), C-C motif ligand 2 (CCL2), and nerve growth factor (NGF) were found to occupy central positions in the interaction network. 
Table 3 Selected genes linked to inflammation, oxidative stress, catabolic enzymes, and extracellular matrix production as well as growth factors in dexamethasone-treated OA chondrocytes (D) relative to control (Co)

\begin{tabular}{|c|c|c|c|c|c|}
\hline \multicolumn{6}{|c|}{ Inflammation and oxidative stress } \\
\hline Gene & Name & $\begin{array}{r}\text { Mean } \\
(\text { Co) }\end{array}$ & $\begin{array}{r}\text { Mean } \\
\text { (D) }\end{array}$ & $\begin{array}{r}\text { Fold } \\
\text { Change }\end{array}$ & FDR $p$ \\
\hline KLF9 & Kruppel like factor 9 & 582.2 & 6410.9 & 10.85 & $<0.0001$ \\
\hline MKP-1 & MAP kinase phosphatase 1 & 695.1 & 7460.0 & 10.48 & $<0.0001$ \\
\hline MKP-2 & MAP kinase phosphatase 2 & 227.2 & 1198.1 & 5.50 & $<0.0001$ \\
\hline TLR2 & Toll like receptor 2 & 120.3 & 617.0 & 4.72 & $<0.0001$ \\
\hline FOXO3 & Forkhead box $\mathrm{O} 3$ & 1541.3 & 6657.3 & 4.29 & $<0.0001$ \\
\hline IRF4 & Interferon regulatory factor 4 & 27.6 & 128.5 & 3.97 & $<0.0001$ \\
\hline IL1R1 & Interleukin 1 receptor type 1 & 3690.2 & 14009.3 & 3.81 & $<0.0001$ \\
\hline PPARG & $\begin{array}{l}\text { Peroxisome proliferator activated } \\
\text { receptor gamma }\end{array}$ & 24.5 & 79.5 & 3.12 & $<0.0001$ \\
\hline IL16 & Interleukin 16 & 573.4 & 1724.3 & 2.95 & $<0.0001$ \\
\hline DUSP5 & Dual specificity phosphatase 5 & 115.6 & 329.9 & 2.79 & $<0.0001$ \\
\hline SOD2 & Superoxide dismutase 2 & 40215.6 & 112308.8 & 2.77 & $<0.0001$ \\
\hline TNFSF15 & TNF superfamily member 15 & 50.5 & 6.0 & -5.98 & $<0.0001$ \\
\hline CCL2 & C-C motif chemokine ligand 2 & 176.3 & 29.9 & -5.43 & $<0.0001$ \\
\hline FGFR3 & Fibroblast growth factor receptor 3 & 1524.2 & 338.9 & -4.50 & $<0.0001$ \\
\hline COX-2 & Cyclooxygenase-2 & 1232.1 & 280.9 & -4.29 & $<0.0001$ \\
\hline IL6 & Interleukin 6 & 25.8 & 4.0 & -3.86 & $<0.0001$ \\
\hline CX3CL1 & C-X3-C motif chemokine ligand 1 & 30.1 & 10.6 & -2.58 & $<0.0001$ \\
\hline IL11 & Interleukin 11 & 30.4 & 8.2 & -2.58 & $<0.0001$ \\
\hline \multicolumn{6}{|c|}{ Catabolic enzymes and their inhibitors } \\
\hline Gene & Name & $\begin{array}{r}\text { Mean } \\
(\text { Co) }\end{array}$ & $\begin{array}{r}\text { Mean } \\
\text { (D) }\end{array}$ & $\begin{array}{r}\text { Fold } \\
\text { Change }\end{array}$ & FDRp \\
\hline MMP7 & Matrix metalloproteinase 7 & 3.3 & 29.0 & 4.89 & $<0.0001$ \\
\hline MMP19 & Matrix metalloproteinase 19 & 9.7 & 31.3 & 2.89 & $<0.0001$ \\
\hline MMP2 & Matrix metalloproteinase 2 & 165.6 & 347.7 & 2.06 & $<0.0001$ \\
\hline MMP13 & Matrix metalloproteinase 13 & 2452.4 & 536.6 & -4.08 & 0.00034 \\
\hline MMP16 & Matrix metalloproteinase 16 & 1004.9 & 323.5 & -3.12 & $<0.0001$ \\
\hline MMP1 & Matrix metalloproteinase 1 & 26580.9 & 9513.7 & -2.85 & $<0.0001$ \\
\hline ADAMTS9 & $\begin{array}{l}\text { ADAM metallopeptidase with } \\
\text { thrombospondin type } 1 \text { motif } 9 \\
\text { ADAM metallopeptidase with }\end{array}$ & 484.4 & 1713.8 & 3.14 & $<0.0001$ \\
\hline ADAMTS1 & $\begin{array}{l}\text { thrombospondin type } 1 \text { motif } 1 \\
\text { ADAM metallopeptidase with }\end{array}$ & 4476.2 & 1022.4 & -4.29 & $<0.0001$ \\
\hline ADAMTS3 & thrombospondin type 1 motif 3 & 207.5 & 70.6 & -2.83 & $<0.0001$ \\
\hline TIMP4 & TIMP metallopeptidase inhibitor 4 & 386.8 & 1717.0 & 4.41 & $<0.0001$ \\
\hline TIMP3 & TIMP metallopeptidase inhibitor 3 & 14668.7 & 6429.5 & -2.35 & $<0.0001$ \\
\hline
\end{tabular}


Table 3 Selected genes linked to inflammation, oxidative stress, catabolic enzymes, and extracellular matrix production as well as growth factors in dexamethasone-treated OA chondrocytes (D) relative to control (Co) (Continued)

\begin{tabular}{|c|c|c|c|c|c|}
\hline \multicolumn{6}{|c|}{ Extracellular matrix components } \\
\hline Gene & Name & $\begin{array}{r}\text { Mean } \\
\text { (Co) }\end{array}$ & $\begin{array}{r}\text { Mean } \\
\text { (D) }\end{array}$ & $\begin{array}{r}\text { Fold } \\
\text { Change }\end{array}$ & FDRp \\
\hline COL13A1 & Collagen type XIII alpha 1 chain & 51.2 & 7.2 & -4.99 & $<0.0001$ \\
\hline COL27A1 & Collagen type XXVII alpha 1 chain & 2220.9 & 468.6 & -4.76 & $<0.0001$ \\
\hline COL9A1 & Collagen type IX alpha 1 chain & 678.5 & 176.2 & -3.66 & $<0.0001$ \\
\hline COL1A1 & Collagen type I alpha 1 chain & 146.3 & 46.8 & -3.12 & $<0.0001$ \\
\hline COL11A1 & Collagen type XI alpha 1 chain & 59852.0 & 19522.6 & -3.12 & $<0.0001$ \\
\hline COL5A1 & Collagen type $V$ alpha 1 chain & 5372.5 & 1790.5 & -2.95 & $<0.0001$ \\
\hline COL14A1 & Collagen type XIV alpha 1 chain & 1474.2 & 562.4 & -2.69 & $<0.0001$ \\
\hline COL16A1 & Collagen type XVI alpha 1 chain & 991.9 & 408.0 & -2.39 & $<0.0001$ \\
\hline COL15A1 & Collagen type XV alpha 1 chain & 9376.8 & 4058.2 & -2.31 & $<0.0001$ \\
\hline COL2A1 & Collagen type II alpha 1 chain & 130240.1 & 56195.3 & -2.28 & $<0.0001$ \\
\hline COL5A2 & Collagen type $V$ alpha 2 chain & 19215.6 & 8756.4 & -2.22 & $<0.0001$ \\
\hline COL10A1 & Collagen type $X$ alpha 1 chain & 2211.9 & 1059.0 & -2.16 & $<0.0001$ \\
\hline COL1A2 & Collagen type I alpha 2 chain & 5477.4 & 2601.9 & -2.11 & $<0.0001$ \\
\hline ACAN & Aggrecan & 81094.4 & 202992.8 & 2.43 & $<0.0001$ \\
\hline ELN & Elastin & 377.4 & 99.1 & -3.78 & $<0.0001$ \\
\hline \multicolumn{6}{|c|}{ Growth factors } \\
\hline Gene & Name & $\begin{array}{r}\text { Mean } \\
\text { (Co) }\end{array}$ & $\begin{array}{r}\text { Mean } \\
\text { (D) }\end{array}$ & $\begin{array}{r}\text { Fold } \\
\text { Change }\end{array}$ & FDRp \\
\hline TDGF1 & Teratocarcinoma -derived growth factor 1 & 4.0 & 30.4 & 5.21 & $<0.0001$ \\
\hline CTGF & Connective tissue growth factor & 16003.3 & 36823.5 & 2.25 & $<0.0001$ \\
\hline PGF & Placental growth factor & 73.6 & 11.4 & -5.13 & $<0.0001$ \\
\hline TGFB3 & Transforming growth factor beta 3 & 318.8 & 63.1 & -4.86 & $<0.0001$ \\
\hline NDP & NDP, norrin cystine knot growth factor & 259.2 & 51.5 & -4.72 & $<0.0001$ \\
\hline FGF1 & Fibroblast growth factor 1 & 6015.9 & 2323.5 & -2.62 & $<0.0001$ \\
\hline TGFB2 & Transforming growth factor beta 2 & 7649.3 & 2938.2 & -2.57 & $<0.0001$ \\
\hline VEGFA & Vascular endothelial growth factor $A$ & 8007.4 & 3366.9 & -2.36 & $<0.0001$ \\
\hline GDF5 & Growth differentiation factor 5 & 474.1 & 229.3 & -2.11 & $<0.0001$ \\
\hline \multicolumn{6}{|c|}{$\begin{array}{l}\text { FDR } p=\text { False discovery rate } \text {-corrected } p \text {-value } \\
\text { Red }=\text { upregulated genes } \\
\text { Blue }=\text { downregulated genes }\end{array}$} \\
\hline
\end{tabular}

\section{Discussion}

The pathology of OA is characterized by eventual cartilage degradation that is caused by imbalanced gene expression profiles in the cartilage. The effects of GCs used in the treatment of OA on this balance are of interest, and RNA-Seq provides a comprehensive view of gene expression in a tissue. Dexamethasone was found to affect the expression of a large number of genes in OA chondrocytes. Among the most strongly affected genes were several involved in inflammation, extracellular matrix organization, and carbohydrate and lipid metabolism.

Constant low-grade joint inflammation along with inflammatory exacerbations is a central feature of OA. Glucocorticoids were found to inhibit inflammation, and this might explain part of their therapeutic effects on OA exacerbations. In our data, dexamethasone reduced the expression of well-known inflammatory factors such as cyclooxygenase-2 (COX-2) [38], interleukin 6 (IL6), and $\mathrm{C}-\mathrm{C}$ motif chemokine ligand 2 (CCL2) [39]. In 


\begin{tabular}{|c|c|c|c|c|c|}
\hline \multicolumn{6}{|c|}{ Regulation of carbohydrate metabolism (GO:0006109) } \\
\hline Gene & Name & $\begin{array}{l}\text { Mean } \\
\text { (Co) }\end{array}$ & $\begin{array}{l}\text { Mean } \\
\text { (D) }\end{array}$ & $\begin{array}{l}\text { Fold } \\
\text { Change }\end{array}$ & FDR $p$ \\
\hline PDK4 & Pyruvate dehydrogenase kinase 4 & 251.6 & 5804.9 & 19.84 & $<0.0001$ \\
\hline ADRA1B & Adrenoceptor alpha 1B & 0.1 & 23.7 & 14.72 & $<0.0001$ \\
\hline KCNJ11 & Potassium voltage-gated channel subfamily J member 11 & 0.3 & 21.6 & 12.13 & $<0.0001$ \\
\hline CLTCL1 & Clathrin heavy chain like 1 & 104 & 693.2 & 6.45 & $<0.0001$ \\
\hline DCXR & Dicarbonyl and $\mathrm{L}-\mathrm{xylu}$ lose reductase & 79 & 196.7 & 2.41 & $<0.0001$ \\
\hline PYGL & Glycogen phosphorylase L & 1785.1 & 4258.4 & 2.38 & $<0.0001$ \\
\hline KCNB1 & Potassium voltage-gated channel subfamily B member 1 & 21 & 54.5 & 2.38 & 0.003 \\
\hline IGFBP5 & Insulin like growth factor binding protein 5 & 2688.8 & 435.7 & -6.07 & $<0.0001$ \\
\hline SLC2A12 & Solute carrier family 2 member 12 & 742.4 & 136.7 & -5.07 & $<0.0001$ \\
\hline sox4 & SRY-box 4 & 1548.9 & 339.8 & -4.59 & $<0.0001$ \\
\hline GALM & Galactose mutarotase & 271.7 & 108.4 & -2.55 & $<0.0001$ \\
\hline \multicolumn{6}{|c|}{ Regulation of lipid metabolism (GO:0019216) } \\
\hline Gene & Name & $\begin{array}{l}\text { Mean } \\
\text { (Co) }\end{array}$ & $\begin{array}{l}\text { Mean } \\
\text { (D) }\end{array}$ & $\begin{array}{l}\text { Fold } \\
\text { Change }\end{array}$ & FDR $p$ \\
\hline$\overline{A B C D} 2$ & ATP binding cassette subfamily D member 2 & 13.8 & 340.3 & 18.77 & $<0.0001$ \\
\hline ABCA6 & ATP binding cassette subfamily A member 6 & 102.4 & 1070.3 & 9.99 & $<0.0001$ \\
\hline SORBS1 & Sorbin and $\mathrm{SH} 3$ domain containing 1 & 648.8 & 4163.1 & 6.36 & $<0.0001$ \\
\hline APOD & Apolipoprotein D & 638.3 & 3819.4 & 6.15 & $<0.0001$ \\
\hline APOB & Apolipoprotein B & 15.7 & 95.5 & 5.16 & $<0.0001$ \\
\hline PRKAG2 & Protein kinase AMP-activated non-catalytic subunit gamma 2 & 470.8 & 1591.1 & 3.29 & $<0.0001$ \\
\hline PPARG & Peroxisome proliferator activated receptor gamma & 24.5 & 79.5 & 3.12 & $<0.0001$ \\
\hline SESN3 & Sestrin 3 & 4701.2 & 14511 & 3.1 & $<0.0001$ \\
\hline FABP4 & Fatty acid binding protein 4 & 124.8 & 374.2 & 2.93 & $<0.0001$ \\
\hline IRS2 & Insulin receptor substrate 2 & 364.5 & 902.6 & 2.39 & $<0.0001$ \\
\hline PLIN2 & Perilipin 2 & 875.4 & 1834.3 & 2.07 & $<0.0001$ \\
\hline FABP3 & Fatty acid binding protein 3 & 624.2 & 241.1 & -2.58 & $<0.0001$ \\
\hline FABP5 & Fatty acid binding protein 5 & 1357.8 & 634.5 & -2.13 & $<0.0001$ \\
\hline
\end{tabular}

FDR $p=$ False discovery rate -corrected $p$-value, Red $=$ upregulated genes, Blue $=$ downregulated genes

\section{$b$}
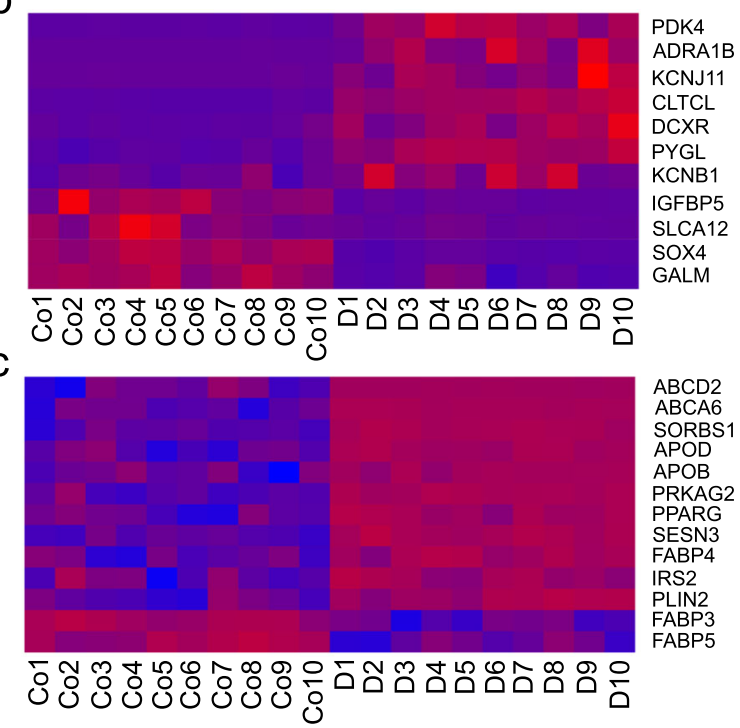

Fig. 1 Genes significantly affected by dexamethasone and regulating carbohydrate (GO:0006109) and lipid (GO:0019216) metabolism. a Table showing the expression of genes regulating carbohydrate and lipid metabolism in dexamethasone-treated OA chondrocytes (D) compared with control (Co). b and $\mathbf{c}$ Heatmaps showing the expression of differentially expressed genes involved in carbohydrate and lipid metabolism, respectively, in dexamethasone-treated OA cells (D) and controls (Co). Expression values are DESeq2-normalized and row-scaled, with blue signifying lower and red higher expression

addition, dexamethasone downregulated the expression of cartilage extracellular matrix-degrading matrix metalloproteinases (MMPs) 1, 13, and 16, while various collagens and anabolic factors (including hyaluronan synthase 2 [HAS2], one of the most strongly downregulated genes) were also downregulated. As the relative expression of catabolic and anabolic factors in the cartilage varies during the course of $\mathrm{OA}$, the effects of glucocorticoids on cartilage homeostasis are likely to depend on the phase of the disease process.

Osteoarthritis as well as glucocorticoid treatment has been reported to be associated with increased oxidative stress and chondrocyte apoptosis [18]. Activation of the ROS/Akt/FOXO3 signaling pathway appears to counteract these effects, and particularly, forkhead box O3 (FOXO3) has been shown to protect chondrocytes from apoptosis [40]. Interestingly, the expression of FOXO3 was strongly upregulated by dexamethasone in the present data. Superoxide dismutase 2 (SOD2) inactivates the superoxide anion, reducing oxidative stress [21]. SOD2 was highly expressed in OA cartilage, and its expression was nearly tripled by treatment with dexamethasone. On the other hand, dexamethasone strongly enhanced the expression of KLF9, which has been shown to sensitize cells to oxidative stress [41] and may contribute to the previously reported dexamethasoneinduced oxidative stress [18].
Pain in OA is mediated through various intracellular pathways and soluble factors, of which nerve growth factor (NGF) is thought to be of particular importance [42]. Antibodies targeting NGF have been shown to be effective for treating OA pain but may also accelerate joint destruction in a small group of patients [36]. In the present data, the expression of NGF was reduced by dexamethasone indicating that intra-articular GC injections might alleviate OA pain at least partly by reducing the synthesis of NGF. The mechanisms of NGF blocker-induced joint degradation are still largely unknown. Increased use of the OA-affected joint, enabled by analgesia, has been hypothesized to explain the findings. However, accelerated degradation has been observed also in non-OA-affected (and initially painless) joints, casting doubt on this hypothesis [36]. Whether GC-induced downregulation of NGF might have similar deleterious effects remains to be studied. In addition to NGF, dexamethasone treatment also downregulated the expression of prostaglandinproducing COX-2 and vascular endothelial growth factor A (VEGFA). Prostaglandins, particularly $\mathrm{PGE}_{2}$, as well as VEGFA are involved in mediating OA pain [43]. Thus, their downregulation by dexamethasone is likely to contribute to the pain-alleviating properties of glucocorticoids in OA. 


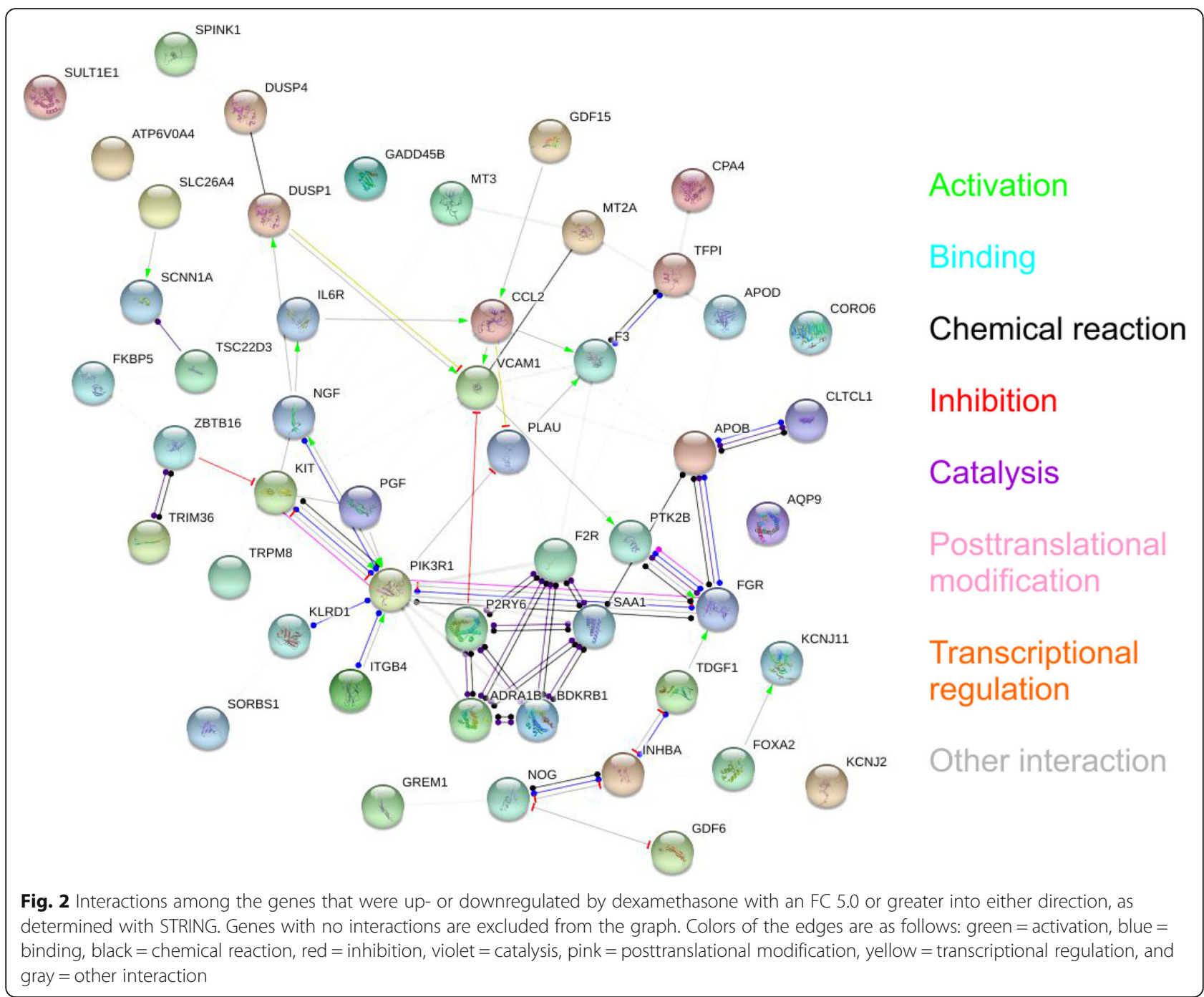

Dexamethasone markedly affected the expression of several genes involved in glucose and lipid metabolism. An interesting example is pyruvate dehydrogenase kinase 4 (PDK4), which was one of the genes most strongly upregulated by dexamethasone. As this gene inactivates pyruvate dehydrogenase and prevents pyruvate produced in glycolysis from progressing to oxidative phosphorylation [44], this glucocorticoid effect may shift carbohydrate metabolism from mitochondrial respiration towards glycolysis. Several genes promoting lipid synthesis and transport, such as perilipin 2 (PLIN2) [45] and 5'-AMPactivated protein kinase subunit gamma-2 (PRKAG2) [46], were also upregulated. However, genes coding for the enzymes participating in the major pathways of carbohydrate and lipid metabolism itself (glycolysis, oxidative phosphorylation, lipolysis, and beta-oxidation) were not significantly affected. Of the OA-associated lipid metabolism genes, apolipoprotein D (APOD) is a central mediator of steroid and lipoprotein metabolism. Its expression has been shown to be decreased in OA chondrocytes [47], and APOD was found to be upregulated by dexamethasone in the present study. Sestrin 3 (SESN3), which was highly expressed in OA cartilage and upregulated by dexamethasone, is involved in the regulation of carbohydrate and lipid metabolism. Impairment of Sestrin signaling has been implicated in the pathogenesis of OA [48]. These are examples of dexamethasone-induced normalization of the expression of lipid metabolism-related genes in $\mathrm{OA}$ chondrocytes. Furthermore, peroxisome proliferator-activated receptor gamma (PPARG), which was likewise upregulated by dexamethasone, is widely regarded as an anti-inflammatory and chondroprotective factor [49] in addition to its significant role in cellular metabolism.

Osteoarthritis has a large heritable component, as up to $50 \%$ of the incidence of the disease is thought to be explained by genetics $[50,51]$. Several genome-wide association (GWAS) studies have been performed in OA [23-25], identifying at least 53 genes associated with the 
disease. Many of the identified genes affect extracellular matrix synthesis and skeletal system development, while the effects of some of the genes are largely unknown [2325]. GWAS studies investigate systemic genomic variation, while expression analyses (such as the present study) directly measure gene expression in the tissue of interest. Nevertheless, as gene polymorphisms often affect the function or activity of the protein coded by the gene, it can be postulated that altered expression or activity of the OA-linked genes might affect the development of the disease and serve as a treatment target. Twelve of the 53 genes previously associated with hip and/or knee $\mathrm{OA}$ in GWAS studies were found to be clearly $(\mathrm{FC}>2.0)$ affected by dexamethasone. Examples of those are COL11A1, COX-2, GDF5, IL6, and VEGFA, all of which were downregulated. Our study identified hundreds of differential genes by dexamethasone, which makes it quite probable that some of them should, by chance, be among those previously linked to OA. However, in the case of those genes which have relatively well-established mechanistic links to OA development, we think that highlighting them as genes potentially mediating the effects of glucocorticoids on the development or symptoms of the disease is justified. For example, GDF5 may affect cartilage remodeling and repair [52], COX-2 and IL6 are indicated to promote inflammation in OA [39], and VEGF-induced angiogenesis seems to play a role in OA progression and pain [42]. Further elucidating the relative glucocorticoid-regulated effects of these genes on OA pathophysiology could be an interesting avenue of further study.

The microarray-based genome-wide expression analysis (GWEA) study by Ramos et al. [9] previously compared the gene expression in $\mathrm{OA}$ affected and preserved cartilage in the same joint. It identified 18 differentially expressed genes, whose up- or downregulation might therefore be expected to affect the pathogenesis of OA. Two of those, namely NGF and collagen 9 alpha 1 (COL9A1), were markedly affected by dexamethasone in the present study. NGF was upregulated in more severely affected OA cartilage [9], and in the present study, dexamethasone was found to downregulate it. As previously discussed, NGF downregulation might alleviate OA pain but also predispose the cartilage to accelerated destruction [36]. COL9A1 was downregulated in severely affected OA cartilage [9], and dexamethasone further downregulated its expression in our data. This can be regarded as an antianabolic effect with an impact on OA, which is further supported by the finding that COL9A1 deficiency induces osteoarthritis-like pathology in mice [53]. The results of our study were also compared with a recent larger, NGS-based expression analysis based on an extended study population [10]. Of the 372 genes identified in that study with markedly differential expression (FC $>2.0$ in either direction) between degraded and preserved OA cartilage, 78 were significantly affected by dexamethasone in our study. While the expression of 42 genes was "normalized" by dexamethasone (i.e., their expression was altered in the direction of preserved cartilage), nearly the same number (34) were altered in the opposite direction. Thus, while glucocorticoids may partially normalize the phenotype of OA chondrocytes, this may be counteracted by increased expression of genes driving the disease process in OA cartilage.

The time course of the effects of glucocorticoids is an important factor to be taken into account when evaluating their potential effects on cartilage. When used at clinically relevant doses $(1-3 \mathrm{mg})$, dexamethasone injected intra-articularly seems to be mostly absorbed from the joint within 24h [54]. We thus propose that the time point used in the current study $(24 \mathrm{~h})$ can be expected to reasonably well capture the effects of glucocorticoids on gene expression in OA chondrocytes, while the effects on protein production are known to occur and last over a longer time frame (several days) [55]. Investigating the time evolution of chondrocyte gene expression in response to glucocorticoid treatment (including direct and secondary effects) would be an interesting avenue of further study.

\section{Conclusions}

In conclusion, dexamethasone was found to cause a major phenotypic switch in OA chondrocytes, while the overall effect on genes linked to OA in GWAS and GWEA studies appeared to be modest. In addition to clear anti-inflammatory, anticatabolic, and extracellular matrix-targeting effects, dexamethasone was found to affect lipid and glucose metabolism-related genes, an observation that might be particularly important in the metabolic phenotype of OA.

\section{Supplementary information}

Supplementary information accompanies this paper at https://doi.org/10. 1186/s13075-020-02289-7.

\footnotetext{
Additional file 1: Table S1. Primers and probes used for quantitative RT-PCR. Table S3. Expression of cartilage constituents in dexamethasone-treated OA chondrocytes (D) relative to controls (Co) Table S4. Selected genes linked to inflammation, oxidative stress, catabolism and extracellular matrix production in dexamethasone-treated OA chondrocytes (D) relative to controls (CO) as determined by NGS and confirmed with RT-PCR. Table S5. Expression of genes belonging to the major pathways of carbohydrate and lipid metabolism in dexamethasone-treated OA chondrocytes (D) relative to controls (Co) [35]. Table S6. Effects of dexamethasone on genes linked to OA in previous GWAS studies [21-23]. Table S7. Effects of dexamethasone on genes previously linked to OA in the GWEA study by Ramos et al. [9]. Table S8. Effects of dexamethasone on genes previously linked to OA cartilage in the GWEA study by Almeida et al. [10]. Figure S1. Effects of dexamethasone on the production of catabolic and proinflammatory factors in $\mathrm{OA}$ chondrocytes. OA chondrocytes / chondrocytes isolated from OA patients were cultured for $24 \mathrm{~h}$ with or without dexamethasone $(1 \mu \mathrm{M})$. MMP-1 (A), MMP-13 (B) and CCL2 (C) levels in the culture media were determined with ELISA. MMP-1 (D), MMP-13 (E) and CCL2 (F) mRNA expression
} 
was studied with quantitative RT-PCR and normalized against GAPDH. The results were compared against control, which was set as $100 \%$. The results are expressed as mean $+\mathrm{SEM}, n=9$. *: $p<0.05,{ }^{* *}: p<0.01$ and ***: $p<0.001$, compared to the untreated control.

Additional file 2: Table S2. All genes differentially expressed in dexamethasone-treated OA chondrocytes (D) relative to controls (Co).

\section{Abbreviations}

ECM: Extracellular matrix; ELISA: Enzyme-linked immunosorbent assay; FC: Fold change; FDR: False discovery rate; GC: Glucocorticoid; GO: Gene Ontology; GWEA: Genome-wide expression analysis; GWAS: Genome-wide association study; MMP: Matrix metalloproteinase; mRNA: Messenger RNA; NGS: Next-generation sequencing; OA: Osteoarthritis; RNA-Seq: RNA sequencing; RT-PCR: Real-time quantitative polymerase chain reaction; SEM: Standard error of the mean

\section{Acknowledgements}

We wish to thank research coordinator Heli Kupari for her skillful assistance with the cartilage samples, Meiju Kukkonen and Salla Hietakangas for their excellent technical assistance and Heli Määttä for great secretarial help.

\section{Authors' contributions}

AP was involved in the conception and design of the study and in the laboratory analyses; he analyzed the data and drafted the manuscript. $T L$ was involved in the design of the study, in the laboratory analyses, in the interpretation of data, and in revising the manuscript. MH was involved in the design of the study, in the laboratory analyses, and in revising the manuscript. TM was involved in the design of the study, in selecting the patients and acquiring patient samples, in the interpretation of the data, and in revising the manuscript. KV was involved in the design of the study, in the interpretation of the data, and in revising the manuscript. EM supervised the study being particularly involved in the conception and design of the study, in the interpretation of the data, and in writing the manuscript. All authors approved the final version of the manuscript.

\section{Funding}

This study was supported by grants from the Finnish Society of Rheumatology, the Tampere Rheumatism Foundation, the competitive research funding of Pirkanmaa Hospital District, the Paulo Foundation, and the Scandinavian Rheumatology Research Foundation. The funders had no role in the study design, data collection and analysis, decision to publish, or preparation of the manuscript.

\section{Availability of data and materials}

The list of all genes significantly affected by dexamethasone is included in Supplementary data (Table S2).

\section{Ethics approval and consent to participate}

The study was approved by the Ethics Committee of Tampere University Hospital, Finland, and carried out in accordance with the Declaration of Helsinki. Written informed consent was obtained from all patients.

\section{Consent for publication}

Not applicable.

\section{Competing interests}

The authors declare no conflict of interest.

\section{Author details}

'The Immunopharmacology Research Group, Faculty of Medicine and Health Technology, Tampere University and Tampere University Hospital, Tampere, Finland. ${ }^{2}$ Coxa Hospital for Joint Replacement, Tampere, Finland.

\section{Received: 5 February 2020 Accepted: 7 August 2020}

\section{Published online: 17 November 2020}

\section{References}

1. Glyn-Jones S, Palmer AJR, Agricola R, Price AJ, Vincent TL, Weinans $H$, et al. Osteoarthritis. Lancet. 2015;386:376-87.
2. Conaghan PG, Cook AD, Hamilton JA, Tak PP. Therapeutic options for targeting inflammatory osteoarthritis pain. Nat Rev Rheumatol. 2019; 15:355-63.

3. Sandy JD, Chan DD, Trevino RL, Wimmer MA, Plaas A. Human genome-wide expression analysis reorients the study of inflammatory mediators and biomechanics in osteoarthritis. Osteoarthr Cartil. 2015;23:1939-45.

4. Maldonado M, Nam J. The role of changes in extracellular matrix of cartilage in the presence of inflammation on the pathology of osteoarthritis. Biomed Res Int. 2013;2013:10.

5. Lewallen EA, Bonin CA, Li X, Smith J, Karperien M, Larson AN, et al. The synovial microenvironment of osteoarthritic joints alters RNA-seq expression profiles of human primary articular chondrocytes. Gene. 2016;591:456-64.

6. Dunn SL, Soul J, Anand S, Schwartz J-M, Boot-Handford RP, Hardingham TE. Gene expression changes in damaged osteoarthritic cartilage identify a signature of non-chondrogenic and mechanical responses. Osteoarthr Cartil. 2016;24:1431-40.

7. Karlsson C, Dehne T, Lindahl A, Brittberg M, Pruss A, Sittinger M, et al. Genome-wide expression profiling reveals new candidate genes associated with osteoarthritis. Osteoarthr Cartil. 2010;18:581-592.

8. Snelling S, Rout R, Davidson R, Clark I, Carr A, Hulley PA, et al. A gene expression study of normal and damaged cartilage in anteromedial gonarthrosis, a phenotype of osteoarthritis. Osteoarthr Cartil. 2014;22:334343.

9. Ramos YFM, den Hollander W, Bovée JVMG, Bomer N, van der Breggen R, Lakenberg N, et al. Genes involved in the osteoarthritis process identified through genome wide expression analysis in articular cartilage; the RAAK Study. PLoS One. 2014;9:e103056..

10. de Almeida RC, Ramos YFM, Mahfouz A, den Hollander W, Lakenberg N

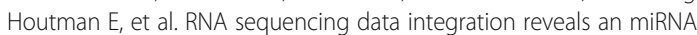
interactome of osteoarthritis cartilage. Ann Rheum Dis. 2019;78:270-7.

11. Bannuru RR, Osani MC, Vaysbrot EE, Arden NK, Bennell K, Bierma-Zeinstra SMA, et al. OARSI guidelines for the non-surgical management of knee, hip, and polyarticular osteoarthritis. Osteoarthr Cartil. 2019;27:1578-89.

12. Hochberg MC, Altman RD, April KT, Benkhalti M, Guyatt G, McGowan J, et al American College of Rheumatology 2012 recommendations for the use of nonpharmacologic and pharmacologic therapies in osteoarthritis of the hand, hip, and knee. Arthritis Care Res (Hoboken). 2012;64:465-74.

13. National Clinical Guideline Centre (UK). Osteoarthritis: care and management in adults. London: National Institute for Health and Care Excellence (UK); 2014.

14. Hirsch G, Kitas G, Klocke R. Intra-articular corticosteroid injection in osteoarthritis of the knee and hip: factors predicting pain relief-a systematic review. Semin Arthritis Rheum. 2013;42:451-73.

15. Jüni $P$, Hari R, Rutjes AWS, Fischer R, Silletta MG, Reichenbach S, et al. Intraarticular corticosteroid for knee osteoarthritis. Cochrane Database Syst Rev. 2015;22:CD005328.

16. McAlindon TE, LaValley MP, Harvey WF, Price LL, Driban JB, Zhang M, et al. Effect of intra-articular triamcinolone vs saline on knee cartilage volume and pain in patients with knee osteoarthritis: a randomized clinical trial. JAMA. 2017;317:1967-75

17. Barnes PJ. Glucocorticosteroids. In: Handbook of experimental pharmacology. Vol 237; 2016. p. 93-115.

18. Suntiparpluacha M, Tammachote N, Tammachote R. Triamcinolone acetonide reduces viability, induces oxidative stress, and alters gene expressions of human chondrocytes. Eur Rev Med Pharmacol Sci. 2016;20: 4985-92.

19. Ruiz-Romero C, Carreira V, Rego I, Remeseiro S, López-Armada MJ, Blanco FJ, Proteomic analysis of human osteoarthritic chondrocytes reveals protein changes in stress and glycolysis. Proteomics. 2008;8:495-507.

20. Choi WS, Lee G, Song WH, Koh JT, Yang J, Kwak JS, et al. The $\mathrm{CH} 25 \mathrm{H}-$ CYP7B1-RORa axis of cholesterol metabolism regulates osteoarthritis. Nature. 2019;566:254-8.

21. Lane RS, Fu Y, Matsuzaki S, Kinter M, Humphries KM, Griffin TM. Mitochondrial respiration and redox coupling in articular chondrocytes. Arthritis Res Ther. 2015;17:54

22. Yuen KCJ, Chong LE, Riddle MC. Influence of glucocorticoids and growth hormone on insulin sensitivity in humans. Diabet Med. 2013;30:651-63.

23. Evangelou E, Kerkhof HJ, Styrkarsdottir U, Ntzani EE, Bos SD, Esko T, et al. A meta-analysis of genome-wide association studies identifies novel variants associated with osteoarthritis of the hip. Ann Rheum Dis. 2014:73:2130-6. 
24. Zeggini E, Panoutsopoulou K, Southam L, Rayner NW, Day-Williams AG, Lopes MC, et al. Identification of new susceptibility loci for osteoarthritis (arcOGEN): a genome-wide association study. Lancet. 2012;380:815.

25. Wang $T$, Liang Y, Li H, Li H, He Q, Xue Y, et al. Single nucleotide polymorphisms and osteoarthritis: an overview and a meta-analysis. Medicine (Baltimore). 2016:95:e2811.

26. Altman $\mathrm{R}$, Asch $\mathrm{E}$, Bloch $\mathrm{D}$, Bole $\mathrm{G}$, Borenstein $\mathrm{D}$, Brandt $\mathrm{K}$, et al. Development of criteria for the classification and reporting of osteoarthritis: classification of osteoarthritis of the knee. Arthritis Rheum. 1986;29:1039-49.

27. Koskinen A, Juslin S, Nieminen R, Moilanen T, Vuolteenaho K, Moilanen E. Adiponectin associates with markers of cartilage degradation in osteoarthritis and induces production of proinflammatory and catabolic factors through mitogen-activated protein kinase pathways. Arthritis Res Ther. 2011;13:R184

28. Andrews S. FastQC: a quality control tool for high throughput sequence data. http://www.bioinformatics.babraham.ac.uk/projects/fastqc. Accessed 1 June 2020.

29. Bolger AM, Lohse M, Usadel B. Trimmomatic: a flexible trimmer for Illumina sequence data. Bioinformatics. 2014;30:2114-20.

30. Dobin A, Davis CA, Schlesinger F, Drenkow J, Zaleski C, Jha S, et al. STAR: ultrafast universal RNA-seq aligner. Bioinformatics. 2013;29:15-21.

31. Liao Y, Smyth GK, Shi W. featureCounts: an efficient general purpose program for assigning sequence reads to genomic features. Bioinformatics. 2014;30:923-30

32. Love Ml, Huber W, Anders S. Moderated estimation of fold change and dispersion for RNA-seq data with DESeq2. Genome Biol. 2014;15:550.

33. Ashburner M, Ball CA, Blake JA, Botstein D, Butler H, Cherry JM, et al. Gene Ontology: tool for the unification of biology. Nat Genet. 2000;25:25-9.

34. Eden E, Navon R, Steinfeld I, Lipson D, Yakhini Z. GOrilla: a tool for discovery and visualization of enriched $\mathrm{GO}$ terms in ranked gene lists. BMC Bioinformatics. 2009;10:48.

35. Szklarczyk D, Franceschini A, Wyder S, Forslund K, Heller D, Huerta-Cepas J, et al. STRING v10: protein-protein interaction networks, integrated over the tree of life. Nucleic Acids Res. 2015:43:D452.

36. Miller RE, Malfait A-M, Block JA. Current status of nerve growth factor antibodies for the treatment of osteoarthritis pain. Clin Exp Rheumatol. 2017;35(Suppl 1):85-7.

37. Berg JM, Jeremy M, Tymoczko JL, Stryer L, Stryer L. Biochemistry. W.H. New York: Freeman; 2002.

38. Wojdasiewicz P, Poniatowski ŁA, Szukiewicz D. The role of inflammatory and anti-inflammatory cytokines in the pathogenesis of osteoarthritis. Mediat Inflamm. 2014;2014:561459.

39. Raghu H, Lepus CM, Wang Q, Wong HH, Lingampalli N, Oliviero F, et al. CCL2/CCR2, but not CCL5/CCR5, mediates monocyte recruitment, inflammation and cartilage destruction in osteoarthritis. Ann Rheum Dis. 2017;76:914-22.

40. Shen C, Cai G-Q, Peng J-P, Chen X-D. Autophagy protects chondrocytes from glucocorticoids-induced apoptosis via ROS/Akt/FOXO3 signaling. Osteoarthr Cartil. 2015;23:2279-2287.

41. Zucker SN, Fink EE, Bagati A, Mannava S, Bianchi-Smiraglia A, Bogner PN, et al. Nrf2 amplifies oxidative stress via induction of Klf9. Mol Cell. 2014;53:916-28.

42. Perrot S. Osteoarthritis pain. Best Pract Res Clin Rheumatol. 2015:29:90-7.

43. Mastbergen SC, Bijlsma JW, Lafeber FP. Selective COX-2 inhibition is favorable to human early and late-stage osteoarthritic cartilage: a human in vitro study. Osteoarthr Cartil. 2005;13:519-26.

44. Kolobova E, Tuganova A, Boulatnikov I, Popov KM. Regulation of pyruvate dehydrogenase activity through phosphorylation at multiple sites. Biochem J. 2001;358:69-77.

45. Conte M, Franceschi C, Sandri M, Salvioli S. Perilipin 2 and age-related metabolic diseases: a new perspective. Trends Endocrinol Metab. 2016;27: 893-903.

46. Willows R, Navaratnam N, Lima A, Read J, Carling D. Effect of different $\gamma$ subunit isoforms on the regulation of AMPK. Biochem J. 2017:474:1741-54.

47. Tew SR, Clegg PD, Brew CJ, Redmond CM, Hardingham TE. SOX9 transduction of a human chondrocytic cell line identifies novel genes regulated in primary human chondrocytes and in osteoarthritis. Arthritis Res Ther. 2007;9:R107.

48. Shen T, Alvarez-Garcia O, Li Y, Olmer M, Lotz MK. Suppression of Sestrins in aging and osteoarthritic cartilage: dysfunction of an important stress defense mechanism. Osteoarthr Cartil. 2017;25:287-96.
49. Fahmi H, Martel-Pelletier J, Pelletier J-P, Kapoor M. Peroxisome proliferatoractivated receptor gamma in osteoarthritis. Mod Rheumatol. 2011;21:1-9.

50. Spector TD, MacGregor AJ. Risk factors for osteoarthritis: genetics. Osteoarthr Cartil. 2004;12(Suppl A):S39-44.

51. Skousgaard SG, Hjelmborg J, Skytthe A, Brandt LPA, Möller S, Overgaard S. Probability and heritability estimates on primary osteoarthritis of the hip leading to total hip arthroplasty: a nationwide population based follow-up study in Danish twins. Arthritis Res Ther. 2015;17:336.

52. Kania K, Colella F, Riemen AHK, Wang H, Howard KA, Aigner T, et al. Regulation of Gdf5 expression in joint remodelling, repair and osteoarthritis. Sci Rep. 2020;10:157.

53. Hu K, Xu L, Cao L, Flahiff CM, Brussiau J, Ho K, et al. Pathogenesis of osteoarthritis-like changes in the joints of mice deficient in type IX collagen. Arthritis Rheum. 2006;54:2891-900.

54. Ekstrand C, Bondesson U, Giving E, Hedeland M, Ingvast-Larsson C, Jacobsen $\mathrm{S}$, et al. Disposition and effect of intra-articularly administered dexamethasone on lipopolysaccharide induced equine synovitis. Acta Vet Scand. 2019;61:28

55. Becker DE. Basic and clinical pharmacology of glucocorticosteroids. Anesth Prog. 2013;60:25-32.

\section{Publisher's Note}

Springer Nature remains neutral with regard to jurisdictional claims in published maps and institutional affiliations.
Ready to submit your research? Choose BMC and benefit from:

- fast, convenient online submission

- thorough peer review by experienced researchers in your field

- rapid publication on acceptance

- support for research data, including large and complex data types

- gold Open Access which fosters wider collaboration and increased citations

- maximum visibility for your research: over $100 \mathrm{M}$ website views per year

At BMC, research is always in progress.

Learn more biomedcentral.com/submissions 